\title{
An Efficient Intelligent Power Detection Method for Photovoltaic System
}

\author{
Ayman M Mansour, Jalal Abdallah, and Mohammad A Obeidat \\ Tafila Technical University, \\ 'IS, Tafila, 66110, \\ Jordan
}

\begin{abstract}
Jordan has experienced a significant increase in both peak load and annual electricity demand within the last decade due to the growth of the economy and population. Photovoltaic (PV) system is one of the most popular renewable energy source in Jordan. PV system is highly nonlinear with unpredictable behavior since it is always subject to many external factors such as severe weather conditions, irradiance level, sheds, temperature, etc. This makes it difficult to maintain maximum power production around its operation ranges.

In this paper, an intelligent technique is used to predict and identify the working ability of the PV system under different weather factors in Tafila Technical University (TTU) in Jordan. It helps in optimizing power productions for different operation points. The PV system in Tafila with size 1 MWp PV generated 5.4 GWh since 2017. It saves about $€ 1.5$ million in three years. A real power data from the PV system and a weather data from world weather online site of TTU location are used in this study. Decision tree technique is employed to identify the relation between the output power and weather factors. The results show that the system accuracy is $82.01 \%$ during the training phase and $93.425 \%$ on the validation set.
\end{abstract}

Keywords-PV system, Decision Tree, weather features, Power, Real Data.

\section{INTRODUCTION}

$\mathrm{H}$ ighly demand for energy makes the electrical power systems grow day by day rapidly. Thus, thinking of establishing new power sources will be the persistent need. A rapid increase in the cost of fossil fuel, which is used in conventional energy sources, makes the decision makers employ a new kind of energy sources with lower cost and environmentally friendly. Alternative Energy (AE) sources such as wind farms, photovoltaic PV technology, biomass, hydropower and many different new power alternatives are used. The geometrical region, environmental issues, natural sources and weather conditions should be taken into account before establishing any type of AE source [1].

The use of renewable energy sources adds additional complexity to power systems and makes them more challenging to the operator. The renewable power generation sources are divided into two categories: the sources, which have similar characteristics to conventional power generation facilities in that they are predictable and controllable, such as hydroelectric generation and biomass; and the variable and intermittent sources, such as wind and solar [2].

The effect of wind and solar renewable sources on power system stability is different from that of the conventional power sources. Wind and solar are depending on variable conditions such as weather conditions, as wind speed and solar irradiance, site dependence and types of generators used [3]. Such weather poses many challenges for system operators to ensure grid stability and reliability.

Jordan experienced a significant increase in both peak load and annual electricity demand within the last decade due to a strong growth of economy and population. The peak load of Jordan's electrical system in 2017 was $3282 \mathrm{MW}$ and increased to be $3724 \mathrm{MW}$ in 2020 . The peak load for the years from 2017 to 2020 is shown in Fig. 1

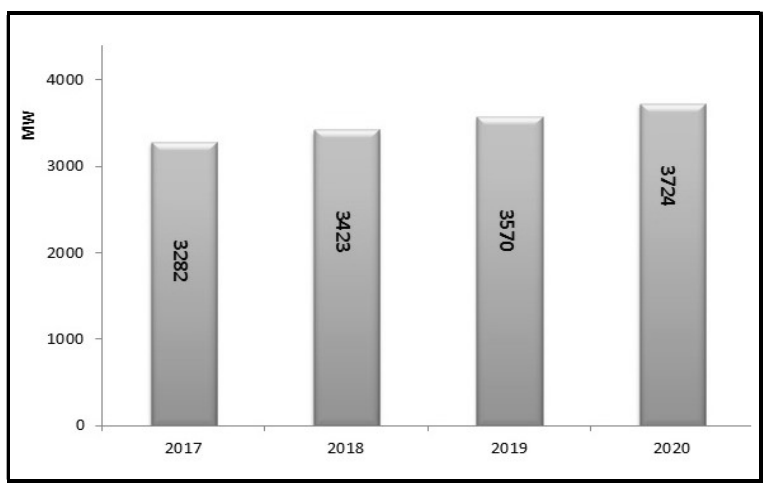

Fig. 1 National grid peak load (2017.2020) [1]

Solar and wind energy systems are one of the most prominent sources of energy, and their utilization has become increasingly popular due to modular and environmental friendly nature [24]. Jordan has a high solar index as shown in Fig. 2. 


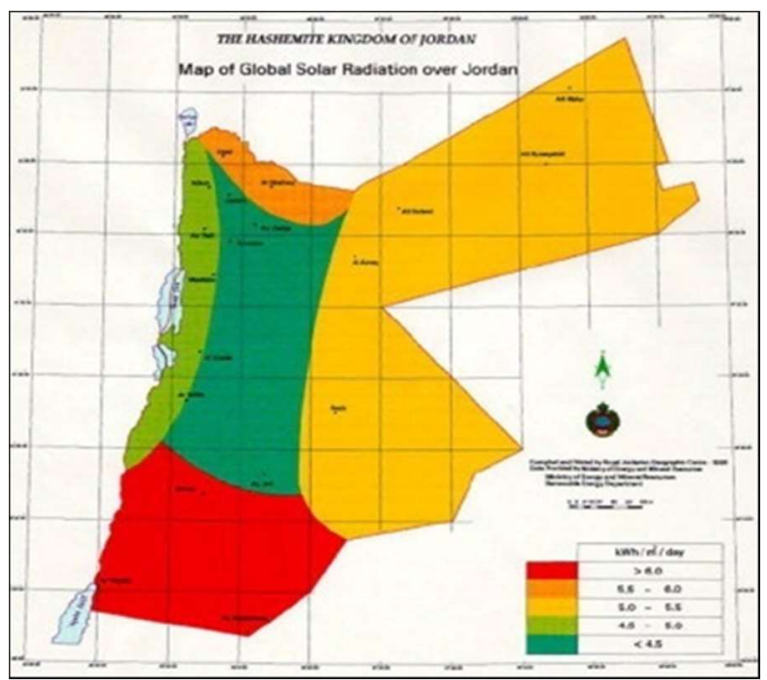

Fig. 2 Global solar radiation over Jordan [1]

Fig. 3 shows the renewable (PV and Wind) energy projects distribution all over Jordan. Most of the RE sources are located in south and far away from the center. The energy is transmitted to the consumer with overhead transmission lines with different voltage levels mainly $132 \mathrm{kV}$ and $400 \mathrm{kV}[1]$.

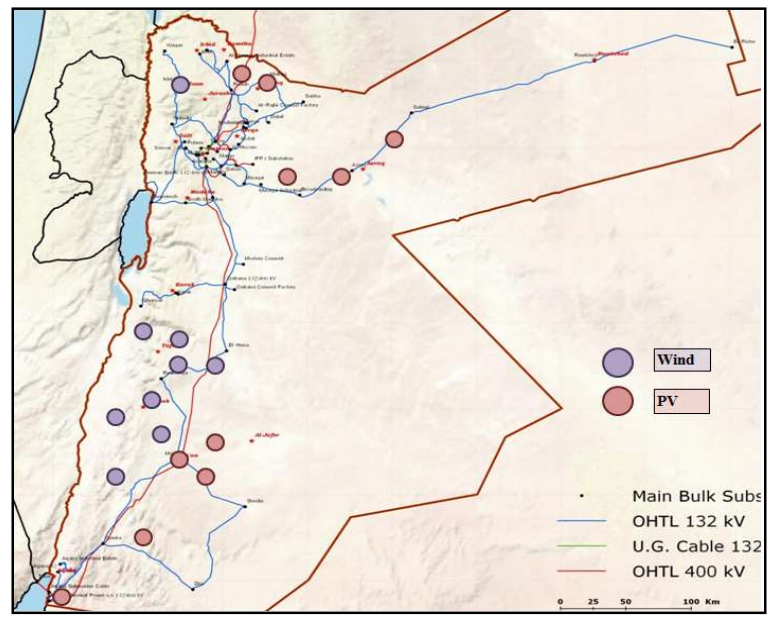

Fig. $3 \mathrm{PV}$ and wind energy project distribution

Nowadays, producing Energy from solar system is very important as the conventional energy has noticeable bad impact on environment. Many methods are used to analyze, develop, design, and control the photovoltaic system. Such methods are very important especially when integrating renewable sources with conventional power [5-7].

The efficiency of a solar panel depends on three main factors: the efficiency of the model used for a particular panel, the number of photovoltaic model inside each solar cell, and the amount of sunlight that the PV panel received. After installing the PV panels, inverters are added to transfer electricity from direct current (DC) to alternating current (AC). The efficiency of a solar panel depends on the solar incident angle. When the sunlight is vertical, the efficiency of any given solar panel is at its maximum.

$\mathrm{PV}$ is very sensitive to high temperatures and dust, which reduces its efficiency. Solar PV is more practical for homes and commercial buildings, while PV technology is very expensive; its cost has decreased dramatically over time, especially in the past five years.

Recent researches are still going on to make PV systems more efficient. Power detection methods are widely used in the literature, but these methods fail under a rapid change in weather conditions. Therefore, many improvements have been made to these algorithms to mitigate inaccurate responses during abrupt changes in the level of sunshine.

Data mining techniques are used recently in many applications because of its benefits to develop models and to make decisions [8-15]. Some methods use artificial intelligent techniques such as artificial neural network as in [16-20]. Other methods use data mining techniques like support vector machine [21-24] and K-nearest neighbor as in [25-27]. In addition, there are some optimization techniques such as genetic algorithm and particle swarm are used to predict and improve the solar system depending on environmental factors such as the temperature, wind, and cloud [28-31].

Authors in [32] deal with similar situation, but they did their analysis of power generated from solar system without considering weather data; instead, they used artificial neural network to predict the power. They claim that the power can be forecasted without using weather data. However, the power generated from PV system is not similar to the conventional power because it is directly depending on weather factors such as temperature, wind, and cloud cover. In addition, they claim that some outliers happened in the system, and they eliminate them. This is not true in the case of PV system since each day has its own weather conditions and sometimes the climate changes suddenly. Such changes affect the power generation, which cannot be considered as outliers. The developed system in this paper solve these problems.

\section{1 MWP TTU PV POWER PLANT}

Jordan government encourages all public universities to invest in solar PV system to decrease their electricity bills. Tafila Technical University started with $1 \mathrm{MWp}$ project in 2016 that cost $€ 1.4$ million. After three years, this successful project has generated 5.4 GWH and save about $€ 1.5$ million. The 1 MWp TTU PV power plant (Fig.4) consists of 3,876 265-Wp PV modules of type SR-P660 245-265 manufactured by Sunrise Energy Co. The modules are distributed on the rooftops of university buildings and car parks inside the university campus as shown in Fig. 4. Four transformers are used in TTU electrical system to supply the output AC power to the buildings as shown in Tables 1. 
Table 1. Transformers of TTU system

\begin{tabular}{|c|c|}
\hline $\begin{array}{l}\text { Transformer } \\
\text { number }\end{array}$ & Building Description \\
\hline Transformer 1 & $\begin{array}{l}\text { Car Park } 1 \\
\text { Engineering Faculty } \\
\text { Girls Hostel } \\
\text { Multi-Function } \\
\text { Building } \\
\text { Science Building } \\
\text { Storage Hunger }\end{array}$ \\
\hline Transformer 2 & $\begin{array}{l}\text { Business College } \\
\text { Labs Hunger } \\
\text { Presidency Building } \\
\text { President Suite }\end{array}$ \\
\hline Transformer 3 & GYM \\
\hline Transformer 4 & $\begin{array}{l}\text { Car Park } 02 \\
\text { Class Room Building }\end{array}$ \\
\hline
\end{tabular}

The system uses 42 inverters distributed in the whole TTU campus as shown in Table 2, all are manufactured by ABB. Out of the 42 inverters 6 are used for photovoltaic car parks. The PV panels are arranged at a tilt angle of $22^{\circ}$ and an azimuth angle of $-16^{\circ}$.

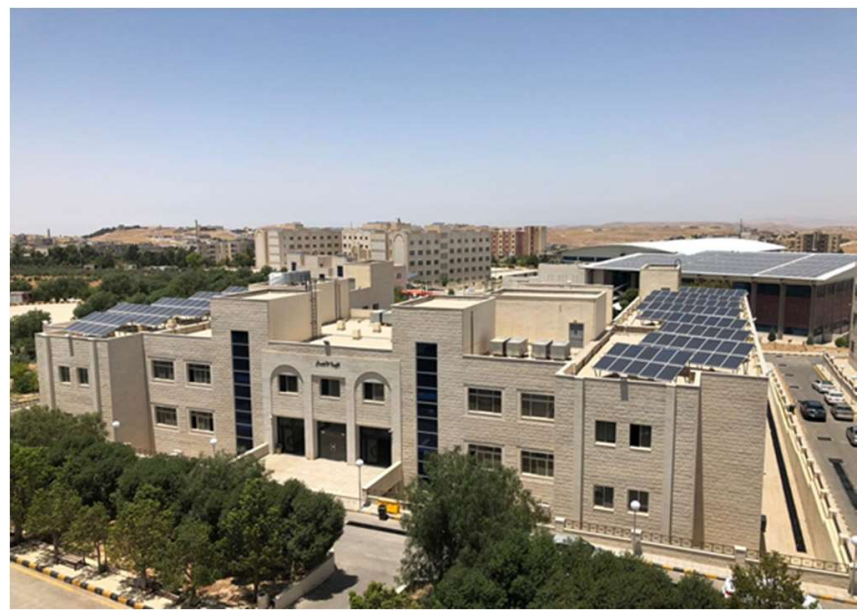

Fig. 4 1MWp TTU PV system for rooftop

From Table 2, it's cleared that all inverters are working within the acceptable range of oversize percentage specified by ABB string configuration report. Such oversizing will not affect the inverter expected lifetime and the inverters operate normally.
Table 2. TTU PV system inverters distributed over all campus building and car parks

\begin{tabular}{|c|c|c|c|c|c|}
\hline $\begin{array}{c}\text { Building } \\
\text { Description }\end{array}$ & $\begin{array}{l}\text { Inverter } \\
\text { Model }\end{array}$ & $\begin{array}{l}\text { Number } \\
\text { of } \\
\text { Inverters }\end{array}$ & $\begin{array}{c}\text { Inverter } \\
\text { Power } \\
\text { (kwp) }\end{array}$ & $\begin{array}{c}\text { Produced } \\
\text { Power } \\
\text { (kwp) in } \\
2019\end{array}$ & $\begin{array}{c}\text { Inverter } \\
\text { Oversize } \\
(\%)\end{array}$ \\
\hline $\begin{array}{c}\text { Business } \\
\text { College } \\
\text { T2 }\end{array}$ & $\begin{array}{l}\text { TRIO } \\
27.6 \mathrm{TL}\end{array}$ & 2 & 55.2 & 60.927 & 10.375 \\
\hline $\begin{array}{c}\text { Car Park } 02 \\
\text { T4 }\end{array}$ & $\begin{array}{l}\text { TRIO } \\
27.6 \mathrm{TL}\end{array}$ & 2 & 55.2 & 59.442 & 7.685386 \\
\hline $\begin{array}{c}\text { Car Park } 1 \\
\text { T1 }\end{array}$ & $\begin{array}{l}\text { TRIO } \\
27.6 \mathrm{TL}\end{array}$ & 4 & 110.4 & 112.668 & 2.054801 \\
\hline \multirow[t]{2}{*}{$\begin{array}{c}\text { Class Room } \\
\text { Building } \\
\text { T4 }\end{array}$} & $\begin{array}{l}\text { PVI- } \\
10.0- \\
\text { OUTD }\end{array}$ & 1 & 10 & 10.825 & 8.258333 \\
\hline & $\begin{array}{l}\text { TRIO } \\
27.6 \mathrm{TL}\end{array}$ & 4 & 110.4 & 93.706 & -15.1209 \\
\hline \multirow[t]{3}{*}{$\begin{array}{c}\text { Engineering } \\
\text { Faculty } \\
\text { T1 }\end{array}$} & $\begin{array}{l}\text { PVI- } \\
12.5- \\
\text { OUTD } \\
\text { Universal }\end{array}$ & 3 & 37.5 & 39.014 & 4.038 \\
\hline & $\begin{array}{l}\text { TRIO } \\
20.0 \mathrm{TL}\end{array}$ & 2 & 40.0 & 41.210 & 3.026875 \\
\hline & $\begin{array}{l}\text { TRIO } \\
27.6 \mathrm{TL}\end{array}$ & 4 & 110.4 & 114.603 & 3.807292 \\
\hline $\begin{array}{c}\text { Girls Hostel } \\
\text { T1 }\end{array}$ & $\begin{array}{l}\text { PVI- } \\
12.5- \\
\text { OUTD }\end{array}$ & 2 & 25 & 28.209 & 12.836 \\
\hline \multirow[t]{2}{*}{$\begin{array}{c}\text { GYM } \\
\text { T3 }\end{array}$} & $\begin{array}{l}\text { TRIO } \\
27.6 \mathrm{TL}\end{array}$ & 8 & 220.8 & 206.288 & -6.57224 \\
\hline & $\begin{array}{l}\text { PVI- } \\
10.0- \\
\text { OUTD }\end{array}$ & 1 & 10 & 9.494 & -5.05083 \\
\hline \multirow[t]{2}{*}{$\begin{array}{c}\text { Labs } \\
\text { Hunger } \\
\text { T2 }\end{array}$} & $\begin{array}{l}\text { PVI- } \\
12.5- \\
\text { OUTD }\end{array}$ & 1 & 12.5 & 12.395 & -0.83267 \\
\hline & $\begin{array}{l}\text { TRIO } \\
27.6 \mathrm{TL}\end{array}$ & 1 & 27.6 & 22.613 & -18.0658 \\
\hline $\begin{array}{c}\text { Multi- } \\
\text { Function } \\
\text { Building T1 }\end{array}$ & $\begin{array}{l}\text { TRIO } 8.5 \\
\text { TL }\end{array}$ & 2 & 17 & 17.294 & 1.732843 \\
\hline $\begin{array}{l}\text { Presidency } \\
\text { Building T2 }\end{array}$ & $\begin{array}{l}\text { RIO } 20.0 \\
\text { TL }\end{array}$ & 1 & 20 & 20.824 & 4.123333 \\
\hline $\begin{array}{l}\text { President } \\
\text { Suite } \\
\text { T2 } \\
\end{array}$ & $\begin{array}{l}\text { PVI- } \\
12.5- \\
\text { OUTD }\end{array}$ & 1 & 12.5 & 12.669 & 1.354667 \\
\hline $\begin{array}{c}\text { Science } \\
\text { Building } \\
\text { T1 }\end{array}$ & $\begin{array}{l}\text { PVI- } \\
12.5- \\
\text { OUTD }\end{array}$ & 1 & 12.5 & 11.715 & -6.27733 \\
\hline \multirow[t]{2}{*}{$\begin{array}{c}\text { Storage } \\
\text { Hunger } \\
\text { T1 }\end{array}$} & $\begin{array}{l}\text { PVI- } \\
12.5- \\
\text { OUTD }\end{array}$ & 1 & 12.5 & 12.1683 & -2.65333 \\
\hline & $\begin{array}{l}\text { TRIO } \\
27.6 \mathrm{TL}\end{array}$ & 1 & 27.6 & 26.620 & -3.54801 \\
\hline Total & & & 871.9 & 912.693 & --- \\
\hline
\end{tabular}

The working principle of a PV plant is simple; photovoltaic cells are connected in series or parallel in order to obtain the desired current and voltage value for the PV module. 
Modules are mounted on structures (typically aluminum anodized) that fix the modules either to the roof or to the ground. Ground mounted systems usually tilt the inclination angle of the modules in order to optimize the radiation input during the year. Roof mounted systems usually fix the modules parallel to the roof if the slope is sufficient for good radiation levels. On the other hand, tilted systems are also available for flat roofs. The modules are interconnected using standard electric copper cables.

Some ground-mounted systems use trackers (one or two axes) in order to follow the sun path and increase the amount of solar radiation received at the surface of the modules. The PV array is then connected to the inverter, which converts direct current (DC) into alternating current (AC). The inverter incorporates Maximum Power Point Trackers (MPPT) in order to follow the constantly changing current and voltage output of the array. The current and voltage output are changing mainly because of changing conditions like irradiance and temperature. The inverter output is then connected to a meter, which registers the amount of energy that has been fed into the grid.

Fig. 5 shows the output AC power generated from one inverter type TRIO 27.6, with generated energy $48.41 \mathrm{MWh}$ from GYM building modules over one-year 2019. The energy produced by TTU PV power plant in 2019 is shown in Fig. 6 .

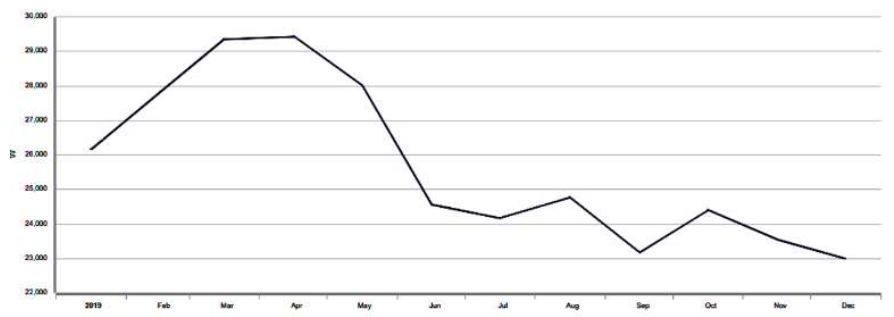

Fig. 5 Output AC power generated from one inverter of GYM building modules, 2019

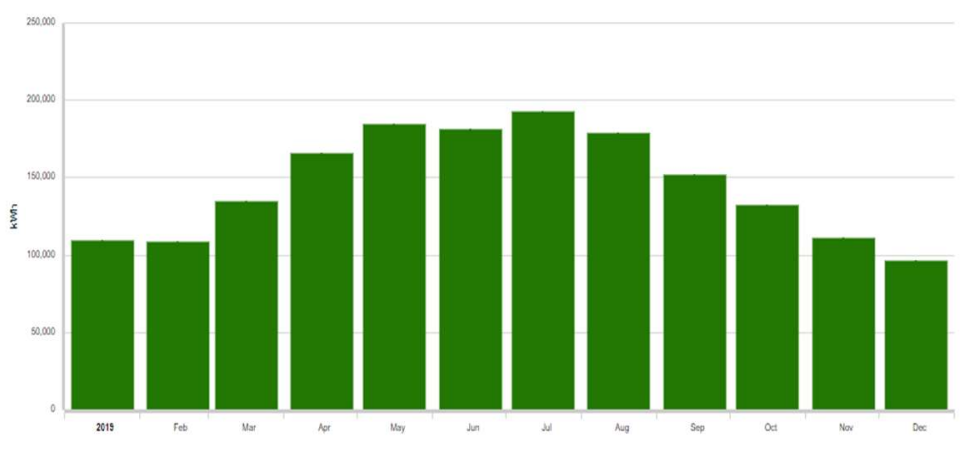

Fig. 6 Energy produced by Tafila Technical University PV power plant in 2019

\section{System Design AND Methodology}

In this paper, output power forecasting system involves five phases: Data gathering and extraction phase, data preprocessing phase, feature selection phase, the learning phase, and the classification phase. In data gathering and extraction, the training and test set are obtained from both Tafila PV system and weather station databases. The second phase is to preprocess the extracted data, including cleaning unnecessarily information, normalizing and labeling. In selected features, dimensionality reduction of the features is being conducted. In the learning phase, the target is to build a model using a part of the data. The last step is using the remaining of the preprocessed data to test the model. A test set is used to determine the accuracy of the model. Fig. 7 shows the block diagram of the developed system phases.

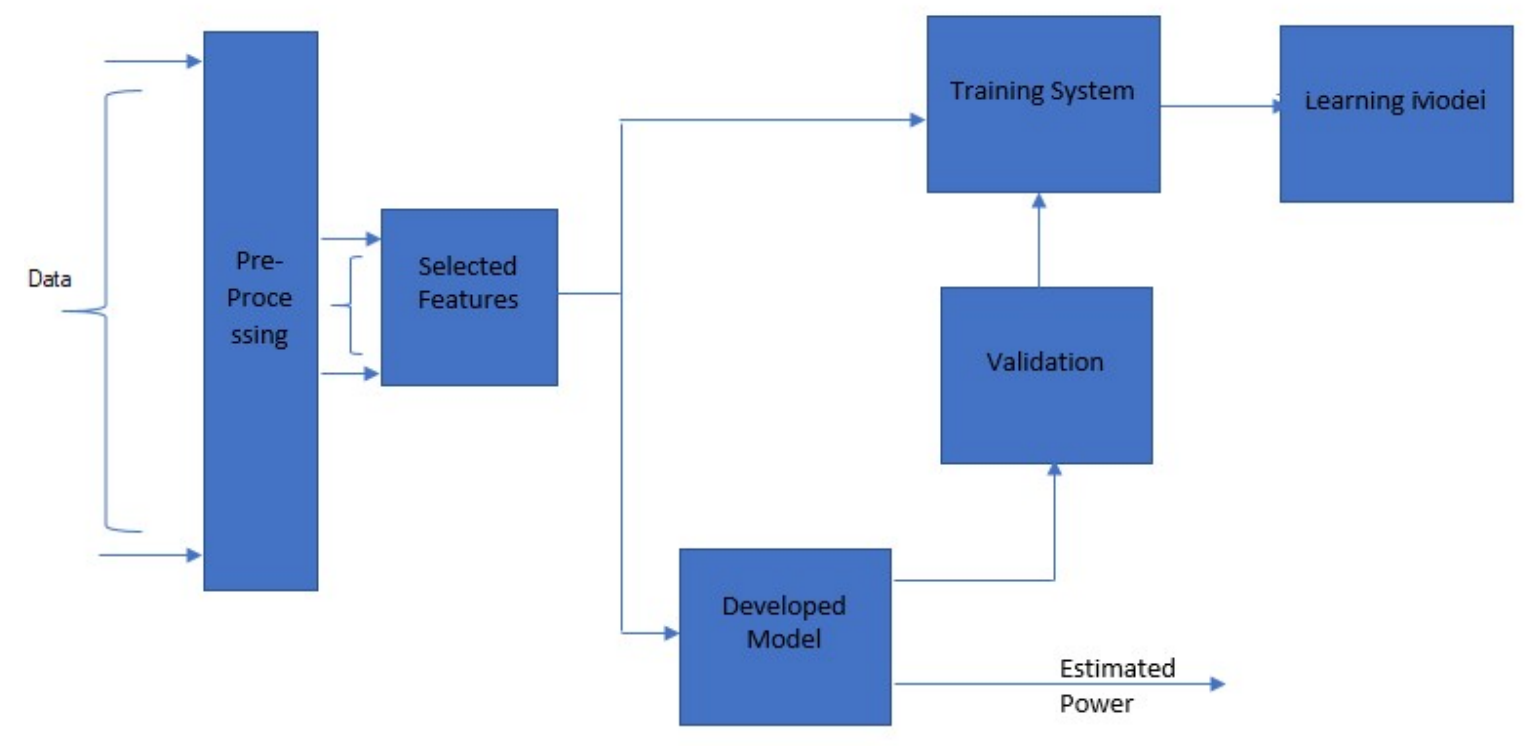

Fig. 7 Block diagram of the developed system phases 


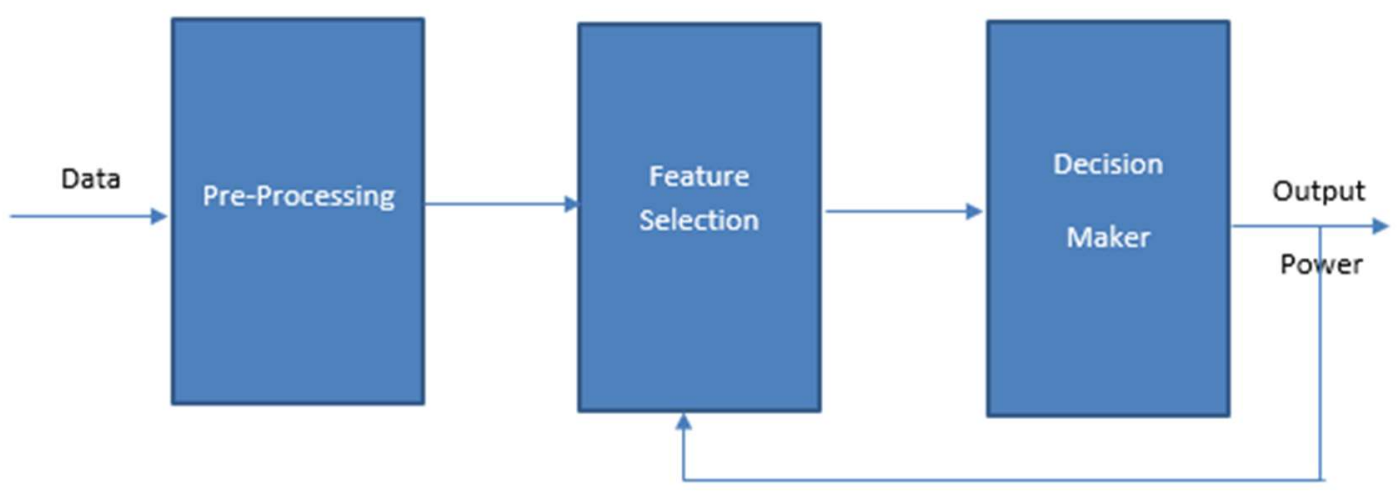

Fig. 8 Training model

The learning model (Fig. 8) is based on Decision Tree. Decision Tree classifier uses the training data to build a tree model that can be used later for classification purposes. Currently, many decision tree algorithms exist including Random Forest, Random Tree, J48, and CART. Based on the output accuracy, the features set is selected. The best set is associated with the higher output power accuracy. There are many different reduction techniques available including Principal Component Analysis (PCA), and Chi-Squared for feature selection and reduction. In this paper, PCA is used as a reduction technique [13],[15].

The extracted data from the databases includes Average Temperature, Wind speed, Humidity, Visibility, Heat index, Pressure, Weather description, cloud cover and generated power. After preprocessing phase and feature selection, six features are used. Five features are used as input features and one feature is used as output class. The six features are Average Temperature, Humidity, Pressure, cloud cover, Heat index and generated output (output class). The Decision maker is based on decision tree classifiers. When a new data values, previously unseen, is presented to the decision maker, the class is predicted based on the training instances. The Decision maker output will be the amount of output power. It has four labels; Very Low, Medium, High, Very High. Fig. 9 shows the testing model block diagram.

A decision tree partition the input space of the dataset into mutually exclusive regions by giving each region a label. The decision tree that consists of a root and internal nodes grows from a root node, by determining the best split that partition the region at internal nodes in to disjoint smaller subset and proceed down to the leaf node (terminal nodes) labeled as - Very Low, Medium, High, and Very High. In order to do the split an error function that quantifies the performance of a node $t$ in separating data from different classes. The used error function is impurity function. The best-known impurity functions for splitting is entropy function and Gini index. By using the impurity Function $\varphi$, the impurity measure of a given node is calculated to do the splitting. Fig 10 shows the steps of decision tree methodology.

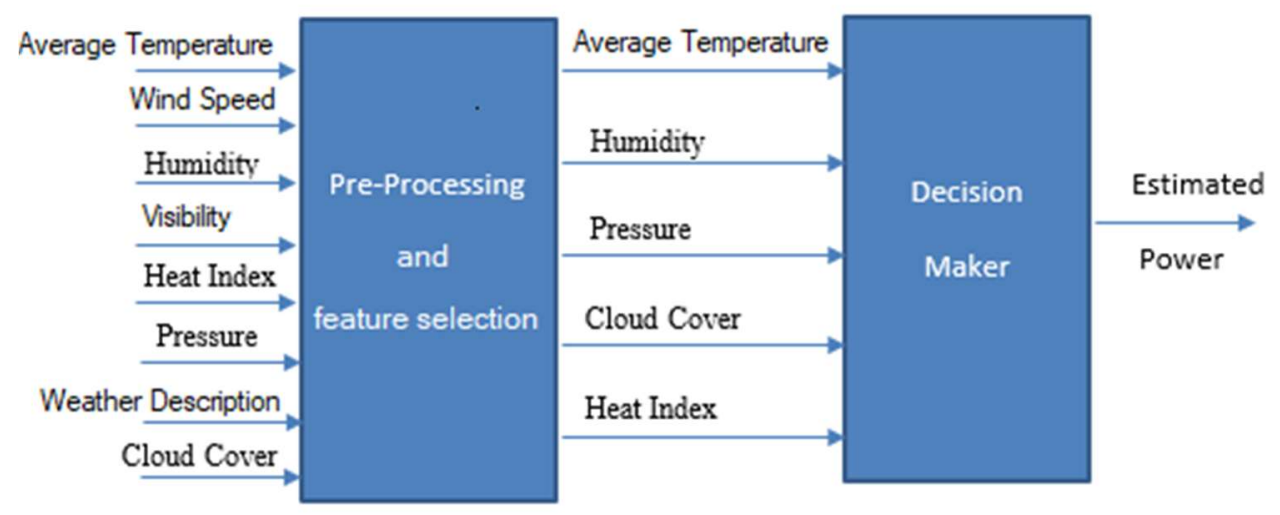

Fig. 9 Testing model 
NTERNATIONAL JOURNAL OF CIRCUITS, SYSTEMS AND SIGNAL PROCESSING

Step 1: Finding the probability of a class $\mathrm{j}$ at node $\mathrm{t}$ such that $p_{j}=P(j \mid t)$

Step 2: Finding the impurity measure of a node

$$
E(t)=\varphi\left(p_{1}, p_{2}, \ldots p_{j}\right)=-\sum_{j=1}^{I} p_{j} \log _{2} p_{j}
$$

Step 3: Finding the impurity measure of a tree $T$ that is expressed as

$$
E(T)=\sum_{t \in \Psi} \frac{n_{t}}{n} E(t)
$$

Where $\Psi$ is the set of terminal nodes in the tree $T$, nt $=$ number of records at child $\mathrm{t}$,

Step 4: Calculating the information gain of Parent Node P (non-leaf node, node with partition)

$$
\begin{aligned}
\operatorname{GAIN}_{\text {Split }} & =E(P)-E(T) \\
= & \mathrm{E}(\mathrm{P})-\sum^{\mathrm{k}} \frac{\mathrm{n}_{\mathrm{i}}}{\mathrm{n}} \mathrm{E}(\mathrm{i})
\end{aligned}
$$

Step 5: Calculating the information gain ratio

$$
\text { GainRATIO }=\frac{\text { GAIN }_{\text {Split }}}{-\sum_{i=1}^{k} \frac{n_{i}}{n} \log _{2} \frac{n i}{n}}
$$

Fig. 10 Decision tree methodology

\section{EXPERIMENTS AND RESULTS}

The data used in this paper is extracted from two databases. The first database is Tafila PV database. This database is provided from inverter manufacture $(\mathrm{ABB})$ as cloud database. The extracted data includes the power produced from the PV system from December, 23th , 2016 to February, 29st 2020. This data includes 1164 records as shown in Fig. 11. Part of the data is shown in Table 3.

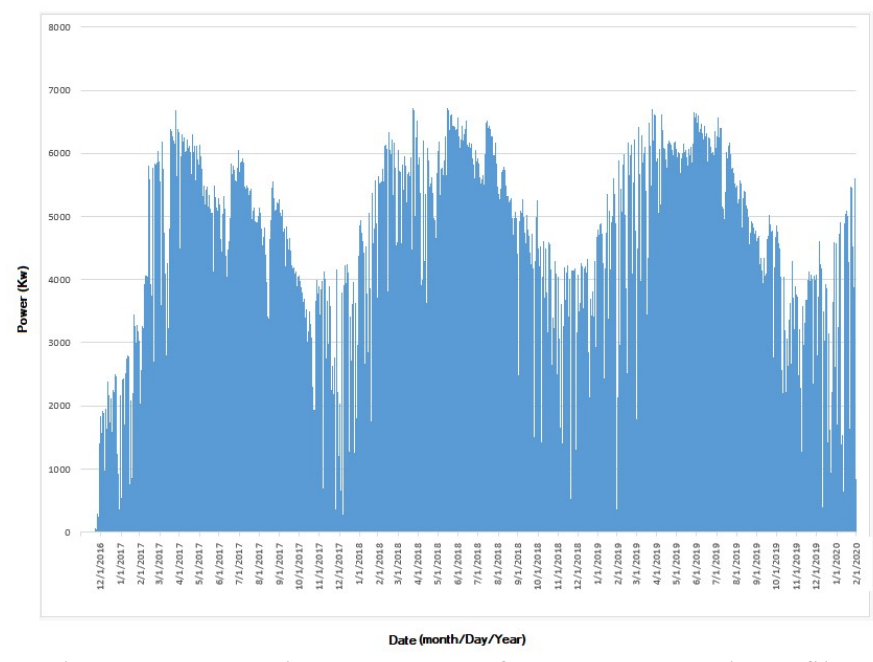

Fig. 11 Generated output power from PV system in Tafila Technical University

Table 3. Tafila PV station Database sample

\begin{tabular}{|l|l|}
\hline Entity Id $\rightarrow$ & 10807492 \\
\hline Entity Name $->$ & Tafila Technical University \\
\hline Field -> & $\begin{array}{l}\text { Generated Energy } \\
\text { kilowatt-hours }\end{array}$ \\
\hline Timestamp & 1707.1 \\
\hline $2 / 1 / 2020$ 0:00 & 3255.1 \\
\hline $2 / 2 / 2020$ 0:00 & 4732.1 \\
\hline $2 / 3 / 20200: 00$ & 3962.7 \\
\hline $2 / 4 / 20200: 00$ & 4807.5 \\
\hline $2 / 5 / 20200: 00$ & 4915.1 \\
\hline $2 / 6 / 20200: 00$ & 1398.1 \\
\hline $2 / 7 / 20200: 00$ & 1532.2 \\
\hline $2 / 8 / 20200: 00$ & 339.4 \\
\hline $2 / 9 / 20200: 00$ & 641.1 \\
\hline $2 / 10 / 20200: 00$ & 3607.5 \\
\hline $2 / 11 / 20200: 00$ & 4892.3 \\
\hline $2 / 12 / 20200: 00$ & 5045.7 \\
\hline $2 / 13 / 20200: 00$ & 4063.4 \\
\hline $2 / 14 / 20200: 00$ & 5096.5 \\
\hline $2 / 15 / 20200: 00$ & 4038.3 \\
\hline $2 / 16 / 20200: 00$ & 5005.4 \\
\hline $2 / 17 / 20200: 00$ & 4270.8 \\
\hline $2 / 18 / 20200: 00$ & \\
\hline & 0.0 \\
\hline
\end{tabular}


Table 4. Weather station database sample

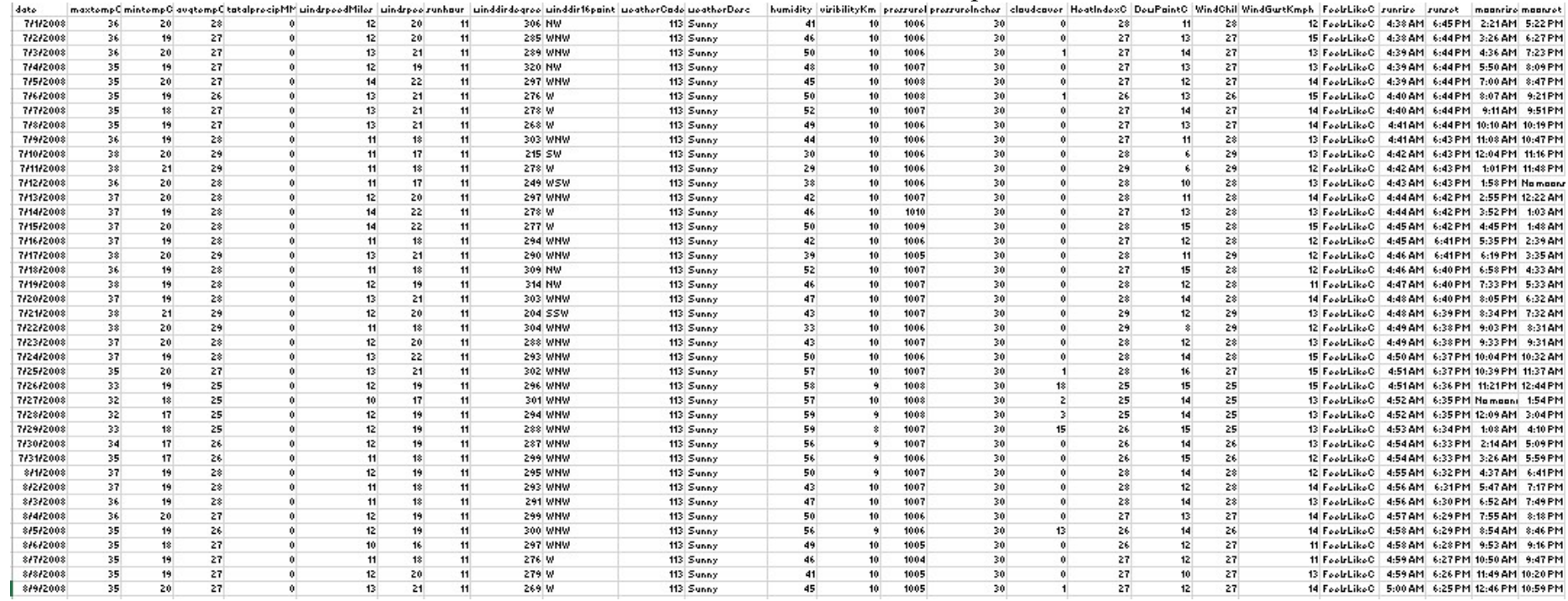

The second database is the weather station database, World Weather Online database. World Weather Online is dedicated to provide global weather forecast and weather content for websites, businesses and the travel industry. This database covers approximately 3 million cities/towns worldwide and its weather forecast is trusted and used by a wide variety of companies and organizations from SME's to large corporate clients. The weather station currently operates two high-tech weather data centers; one situated in Denmark and the other in Germany. The station delivers reliable and accurate weather information for any geo-point in the world. The used weather model is run along with other metrological models like European Centre for Medium-Range Weather Forecasts, World Meteorological Organization, NASA weather satellite imagery, NOAA GFS2 model and JMA model for research and training purposes. It deliver the most accurate weather forecast possible. The extracted data from weather station includes many features such as maxtempC, mintempC, avgtempC, totalprecipMM, windspeedKmph, sunhour winddirdegree, weatherDesc, humidity, visibilityKm pressure $\mathrm{MB}$, cloudcover, heatIndexC, dewPointC, windChillC, windGustKmph, feelsLikeC, sunrise, sunset, moonrise, and moonset. A sample from the weather database is shown in Table 4.

In this paper, just eight weather features are used. These features avgtempC, windspeedKmph, weatherDesc, humidity, visibilityKm pressureMB, cloudcover, and HeatIndexC. The other features has been eliminated.

Fig. 12, Fig. 13, Fig. 14 and Fig. 15 show examples of the extracted features. It shows the weather data from July $1^{\text {st }}$, 2008 to Februry, 12, 2020 (4232 records) for Tafila Technical University location where the PV system is located.

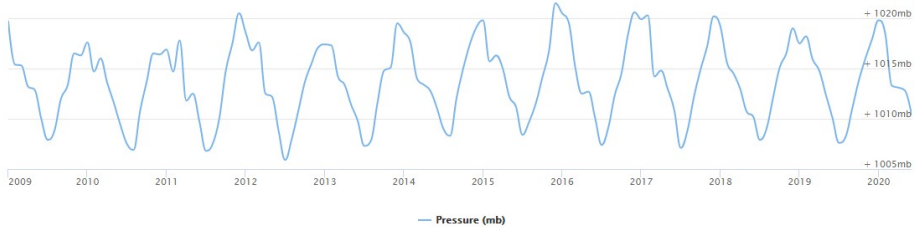

Fig. 12 Pressure data

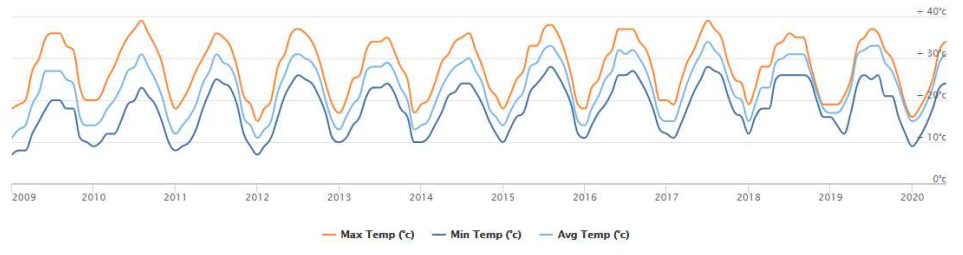

Fig. 13 Temperature data

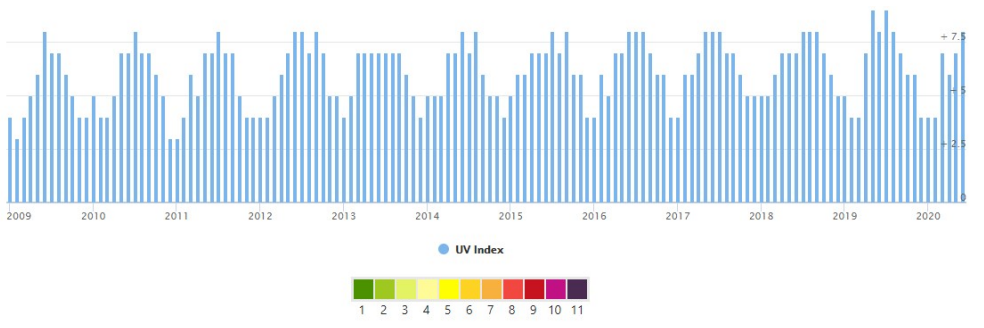

Fig. 14 UV Index data

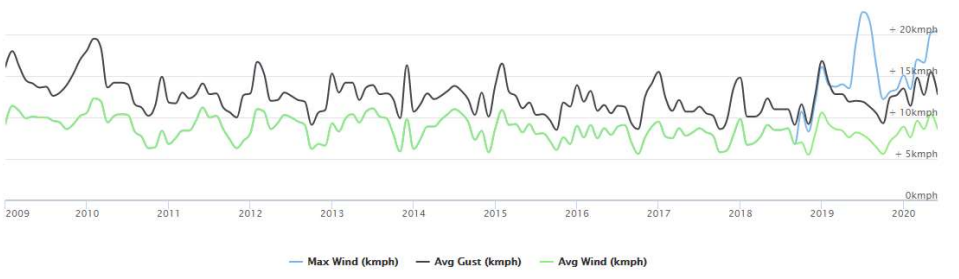

Fig. 15 Wind data 
Table 5. Bended database (Weather database and PV system database)

\begin{tabular}{|c|c|c|c|c|c|c|c|c|c|c|}
\hline $\begin{array}{l}\text { 1: date } \\
\text { Nominal }\end{array}$ & $\begin{array}{l}\text { 2: Avg temp } \\
\text { Numeric }\end{array}$ & $\begin{array}{l}\text { 3: wind speed } \\
\text { Numeric }\end{array}$ & $\begin{array}{l}\text { 4: sun hour } \\
\text { Numeric }\end{array}$ & $\begin{array}{c}\text { 5: weather Descp } \\
\text { Nominal }\end{array}$ & $\begin{array}{l}\text { 6: humidity } \\
\text { Numeric }\end{array}$ & $\begin{array}{l}\text { 7: visibility } \mathrm{Km} \\
\text { Numeric }\end{array}$ & $\begin{array}{l}\text { 8: pressure MB } \\
\text { Numeric }\end{array}$ & $\begin{array}{l}\text { 9: cloud cover } \\
\text { Numeric }\end{array}$ & $\begin{array}{l}\text { 10: Heat Index C } \\
\text { Numeric }\end{array}$ & $\begin{array}{l}\text { 11: Power out } \\
\text { Nominal }\end{array}$ \\
\hline $2 / 28 / 2017$ & 22.0 & 17.0 & 11.0 & Partly cloudy & 24.0 & 10.0 & 1011.0 & 13.0 & 22.0 & very low \\
\hline $3 / 1 / 2017$ & 19.0 & 10.0 & 11.0 & Sunny & 49.0 & 10.0 & 1010.0 & 9.0 & 19.0 & very low \\
\hline $3 / 2 / 2017$ & 18.0 & 12.0 & 11.0 & Sunny & 52.0 & 10.0 & 1015.0 & 3.0 & 18.0 & very low \\
\hline $3 / 4 / 2017$ & 17.0 & 9.0 & 11.0 & Sunny & 50.0 & 10.0 & 1018.0 & 1.0 & 18.0 & meduim \\
\hline $3 / 5 / 2017$ & 18.0 & 9.0 & 11.0 & Sunny & 42.0 & 10.0 & 1018.0 & 0.0 & 18.0 & meduim \\
\hline $3 / 6 / 2017$ & 20.0 & 12.0 & 11.0 & Sunny & 29.0 & 10.0 & 1015.0 & 1.0 & 20.0 & meduim \\
\hline $3 / 9 / 2017$ & 23.0 & 11.0 & 11.0 & Sunny & 20.0 & 10.0 & 1012.0 & 0.0 & 22.0 & high \\
\hline $3 / 10 / 2017$ & 20.0 & 11.0 & 11.0 & Sunny & 46.0 & 10.0 & 1008.0 & 2.0 & 20.0 & high \\
\hline $3 / 11 / 2017$ & 18.0 & 27.0 & 11.0 & Sunny & 39.0 & 10.0 & 1010.0 & 7.0 & 19.0 & meduim \\
\hline $3 / 12 / 2017$ & 21.0 & 31.0 & 11.0 & Sunny & 30.0 & 10.0 & 1012.0 & 3.0 & 20.0 & meduim \\
\hline $3 / 13 / 2017$ & 18.0 & 14.0 & 11.0 & Sunny & 42.0 & 10.0 & 1018.0 & 4.0 & 18.0 & high \\
\hline $3 / 14 / 2017$ & 17.0 & 9.0 & 11.0 & Sunny & 44.0 & 10.0 & 1019.0 & 0.0 & 17.0 & very high \\
\hline $3 / 15 / 2017$ & 17.0 & 21.0 & 11.0 & Sunny & 47.0 & 10.0 & 1015.0 & 6.0 & 17.0 & very high \\
\hline $3 / 20 / 2017$ & 16.0 & 10.0 & 11.0 & Sunny & 48.0 & 10.0 & 1017.0 & 3.0 & 16.0 & very high \\
\hline $3 / 21 / 2017$ & 19.0 & 8.0 & 11.0 & Sunny & 32.0 & 10.0 & 1015.0 & 22.0 & 19.0 & meduim \\
\hline $3 / 22 / 2017$ & 20.0 & 20.0 & 11.0 & Sunny & 32.0 & 10.0 & 1010.0 & 23.0 & 20.0 & meduim \\
\hline $3 / 23 / 2017$ & 20.0 & 9.0 & 11.0 & Sunny & 36.0 & 10.0 & 1010.0 & 11.0 & 20.0 & high \\
\hline $3 / 24 / 2017$ & 18.0 & 10.0 & 11.0 & Sunny & 40.0 & 10.0 & 1015.0 & 1.0 & 18.0 & very high \\
\hline $3 / 25 / 2017$ & 19.0 & 11.0 & 11.0 & Sunny & 41.0 & 10.0 & 1016.0 & 1.0 & 19.0 & very high \\
\hline $3 / 26 / 2017$ & 20.0 & 9.0 & 11.0 & Sunny & 41.0 & 10.0 & 1017.0 & 1.0 & 20.0 & very high \\
\hline $3 / 27 / 2017$ & 20.0 & 10.0 & 11.0 & Sunny & 37.0 & 10.0 & 1016.0 & 19.0 & 20.0 & high \\
\hline $3 / 28 / 2017$ & 20.0 & 9.0 & 11.0 & Sunny & 29.0 & 10.0 & 1016.0 & 16.0 & 20.0 & very high \\
\hline
\end{tabular}

A normalization is applied to the output power values in order to label them. The power values are normalized to values between zero and one. Each generated output power is assigned as a level that belongs to one of the four levels, i.e., The levels are shown below:

- Level 1: value from 0.00 to 0.39 represents Very Low generated power amount.

- Level 2: value from 0.40 to 0.59 represents Medium Similarity generated power amount.

- Level 3: value from 0.60 to 0.79 represents High Similarity generated power amount.

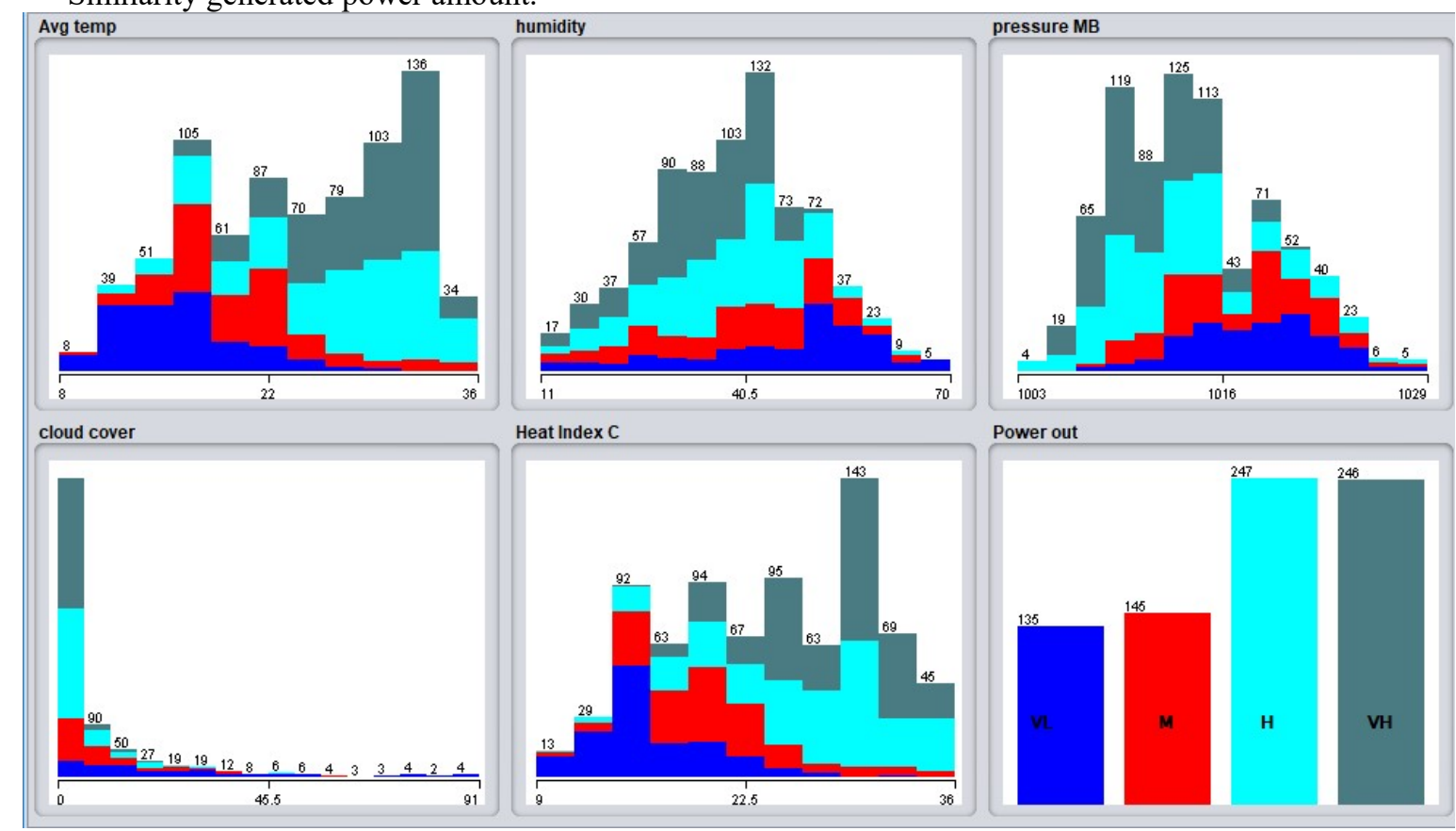

Fig. 16 Input data histogram
- Level 4: value from 0.80 to 1.0 represents Very High Similarity generated power amount.

The blended database has been constructed from the two databases in order to train and test the decision maker model after assigning the power output level for each record. Table 5 shows some records from the bended database.

Fig. 16 shows the histogram of five feature with a projection of output power label presented as colors. 
In this study, WEKA (Waikato Environment for Knowledge Analysis) is used to construct decision trees according to the training set with the standard algorithm J48. Weka is a popular suite of machine learning software written in Java, developed at the University of Waikato, New Zealand. Weka is a free software tool available under the GNU General Public License. It contains a collection of visualization tools and algorithms for data analysis and predictive modelling that support data preprocessing, clustering, classification, regression, visualization, and feature selection. Weka has a powerful Graphical User Interface that supports its functionality.

Once the features are extracted and grouped into a feature vector, classification takes place, where the output power values are classified in one of the following classes: Very Low, Medium, High, Very High. J48 (C4.5) is an algorithm used to generate a decision tree. It has been developed by John Ross Quinlan [33]. C4.5 is an extension of Quinlan's earlier ID3 algorithm. The decision trees generated by $\mathrm{C} 4.5$ is normally used for classification. It has been ranked first in the Top 10 Algorithms in Data Mining algorithm [34].

Java was selected as the development language, and J2SDK version 1.6.0_22 was used for the Java running environment. Access database 2013 is adopted for the development of database. Java database connectivity (JDBC), an applicationprogramming interface for the Java programming language, is used to access the database. JDBC could wrap a structured query language (SQL) statement, send it to the database, and retrieve the desire.

Part of extracted data from January, $1^{\text {st }}, 2017$ to February 12, 2020 (774 records excluding 2018 in order to be used later for validation) has been used for training and testing the decision maker module. The confusion matrix for each class (Very Low, Medium, High Very High) is constructed. The confusion matrix has the form shown in Table 6.

Table 6. Confusion matrix

\begin{tabular}{llllllll} 
& Very & \multicolumn{2}{l}{ Medium } & High & \multicolumn{2}{l}{ Very } \\
Low & \multicolumn{5}{c}{ High } \\
Very Low & a & b & c & D & Sum_r1 \\
\hline Medium & e & f & g & H & Sum_r2 \\
\hline High & i & j & k & L & Sum_r3 \\
\hline $\begin{array}{l}\text { Very } \\
\text { High }\end{array}$ & m & n & o & P & Sum_r4 \\
\hline Sum & Sum_c1 & Sum_c2 & Sum_c3 & Sum_c4 & Total \\
\hline
\end{tabular}

10-fold cross validation is used in this paper. In K-fold the training set will be randomly splitted into $\mathrm{K}$ sets that have approximately the same size. Then the Decision Tree will be trained using (K-2) subset. One of the two remaining subsets will be used for validation and the last for testing. This process will be repeated $\mathrm{K}$ times, while a different subset is used for testing and validation.

The performance measurements used for this paper are recall, precision, classifier F1 rating and accuracy. They are defined as follows:
Recall (R) is the ratio of the relevant data among the retrieved. Precision (P) is the ratio of the accurate data among the retrieved data. Their formulas are given as follow:

$\boldsymbol{R e c a l l}(\boldsymbol{R})=\frac{T_{P}}{T_{P}+F_{N}}$ if $\mathrm{TP}+\mathrm{FN}>0$, otherwise undefined.

The recall of a class "Very Low" is defined as:

$R_{\text {Very Low }}=\frac{a}{\text { Sum_C1 }}$

$\operatorname{Precision}(\boldsymbol{P})=\frac{\boldsymbol{T}_{\boldsymbol{P}}}{\boldsymbol{T}_{\boldsymbol{P}}+\boldsymbol{F}_{\boldsymbol{P}}} \quad$ if $\mathrm{TP}+\mathrm{FN}>0$, otherwise undefined. The precision of a class "Very Low" is defined as:

$P_{\text {Very Low }}=\frac{a}{\text { Sum_r1 }}$

Classifier F1 rating is the harmonic mean of the classifier recall and the precision. It is given as

$$
\boldsymbol{F}_{1}=\frac{2 * \boldsymbol{P} * \boldsymbol{R}}{\boldsymbol{P}+\boldsymbol{R}}
$$

where $\mathrm{R}$ represents the recall, , and $\mathrm{P}$ represents the precision

Accuracy, which indicates the fraction of correctly classified samples among all the samples, obtained by:

$$
\begin{aligned}
\text { Accuracy } & =\frac{\boldsymbol{T}_{\boldsymbol{P}}+\boldsymbol{T}_{\boldsymbol{N}}}{\boldsymbol{T}_{\boldsymbol{P}}+\boldsymbol{T}_{\boldsymbol{N}}+\boldsymbol{F}_{\boldsymbol{P}}+\boldsymbol{F}_{\boldsymbol{N}}} \\
& =\frac{a+f+k+P}{\text { Total }}
\end{aligned}
$$

Kappa statistic is used to give the agreement between developed model and the actual PV system. A Kappa score ranges between 1 which shows full agreement and 0 which shows no agreement. Table 7 shows the resulted power output evaluation results.

Table 7. Overall performance results (training and testing set).

\begin{tabular}{|l|l|}
\hline $\begin{array}{l}\text { Correctly Classified Instances } \\
\text { Correctly }\end{array}$ & Classified \\
$\begin{array}{l}\text { Percentage } \\
\text { Incorrectly }\end{array}$ & $82.0181 \%$ \\
\hline $\begin{array}{l}\text { Instances } \\
\text { Incorrectly }\end{array}$ & Classified \\
$\begin{array}{l}\text { Percentage } \\
\text { Kappa statistic }\end{array}$ & 139 \\
\hline $\begin{array}{l}\text { Mean absolute error } \\
\text { Root mean squared error }\end{array}$ & $17.9819 \%$ \\
\hline $\begin{array}{l}\text { Relative absolute error } \\
\text { Root relative squared error }\end{array}$ & 0.7547 \\
\hline Total Number of Instances & 0.1356 \\
\hline
\end{tabular}

Another performance indicated by confusion matrix is shown in Table 8. This confusion matrix is built based on data testing. 
We constructed the confusion matrix for each class (Very Low, Medium, High, Very High).

Table 8. Confusion matrix (training and testing set).

\begin{tabular}{|c|c|c|c|c|c|}
\hline \multirow{2}{*}{$\begin{array}{l}\text { Output } \\
\text { Power }\end{array}$} & \multicolumn{5}{|c|}{ Real System } \\
\hline & & $\begin{array}{l}\text { Very } \\
\text { Low }\end{array}$ & Medium & High & $\begin{array}{l}\text { Very } \\
\text { High }\end{array}$ \\
\hline \multirow{4}{*}{$\begin{array}{l}\bar{g} \\
\frac{0}{8} \\
\Sigma\end{array}$} & $\begin{array}{l}\text { Very } \\
\text { Low }\end{array}$ & 128 & 3 & 4 & 0 \\
\hline & Medium & 19 & 112 & 11 & 3 \\
\hline & High & 6 & 9 & 182 & 50 \\
\hline & $\begin{array}{l}\text { Very } \\
\text { High }\end{array}$ & 5 & 8 & 21 & 212 \\
\hline
\end{tabular}

The performance measurements result is shown in Table 9 .

Table 9. Performance measurements

\begin{tabular}{|l|l|l|l|l|l|}
\hline $\begin{array}{l}\text { TP } \\
\text { Rate }\end{array}$ & $\begin{array}{l}\text { FP } \\
\text { Rate }\end{array}$ & Precision & Recall & $\begin{array}{l}\text { F- } \\
\text { Measure }\end{array}$ & Class \\
\hline $\mathbf{0 . 9 4 8}$ & 0.04 & 0.810 & 0.948 & 0.874 & $\begin{array}{l}\text { very } \\
\text { low }\end{array}$ \\
\hline $\mathbf{0 . 7 7 2}$ & 0.03 & 0.848 & 0.772 & 0.809 & Medium \\
\hline $\mathbf{0 . 7 3 7}$ & 0.06 & 0.835 & 0.737 & 0.783 & High \\
\hline $\mathbf{0 . 8 6 2}$ & 0.10 & 0.800 & 0.862 & 0.830 & $\begin{array}{l}\text { very } \\
\text { high }\end{array}$ \\
\hline
\end{tabular}

There is excellent agreement if the Kappa coefficient is greater than 0.75 , poor agreement for Kappa coefficient less than 0.4, and fair to good agreement for kappa coefficient between 0.40 and 0.75 . In this paper, Kappa coefficient is 0.75 , which shows excellent agreement.

As the number of features in database was eight features, we used PCA dimensionality reduction method, and we selected around $63 \%$ of the features ( 5 features) with the highest importance. The Accuracy percentage for each number of features is shown in Table 10.

Table 10. Feature selection

\begin{tabular}{|l|l|}
\hline Number of Features & Accuracy $(\%)$ \\
\hline 2 & $64.32 \%$ \\
\hline 3 & $71.53 \%$ \\
\hline 4 & $73.75 \%$ \\
\hline 5 & $82.01 \%$ \\
\hline 6 & $82.01 \%$ \\
\hline 7 & $82.01 \%$ \\
\hline 8 & $82.01 \%$ \\
\hline
\end{tabular}

Using another 365 cases from January, ${ }^{\text {st }}, 2018$ to December $31^{\text {st }} 2018$ from the original extracted databases not previously used in the training or used in cross validation. Table 11 shows 44 records of these cases as an example with both real system output level value and the model output. Fig. 17 shows a part of the learned decision tree associated with these records which is triggered to make power output decision.

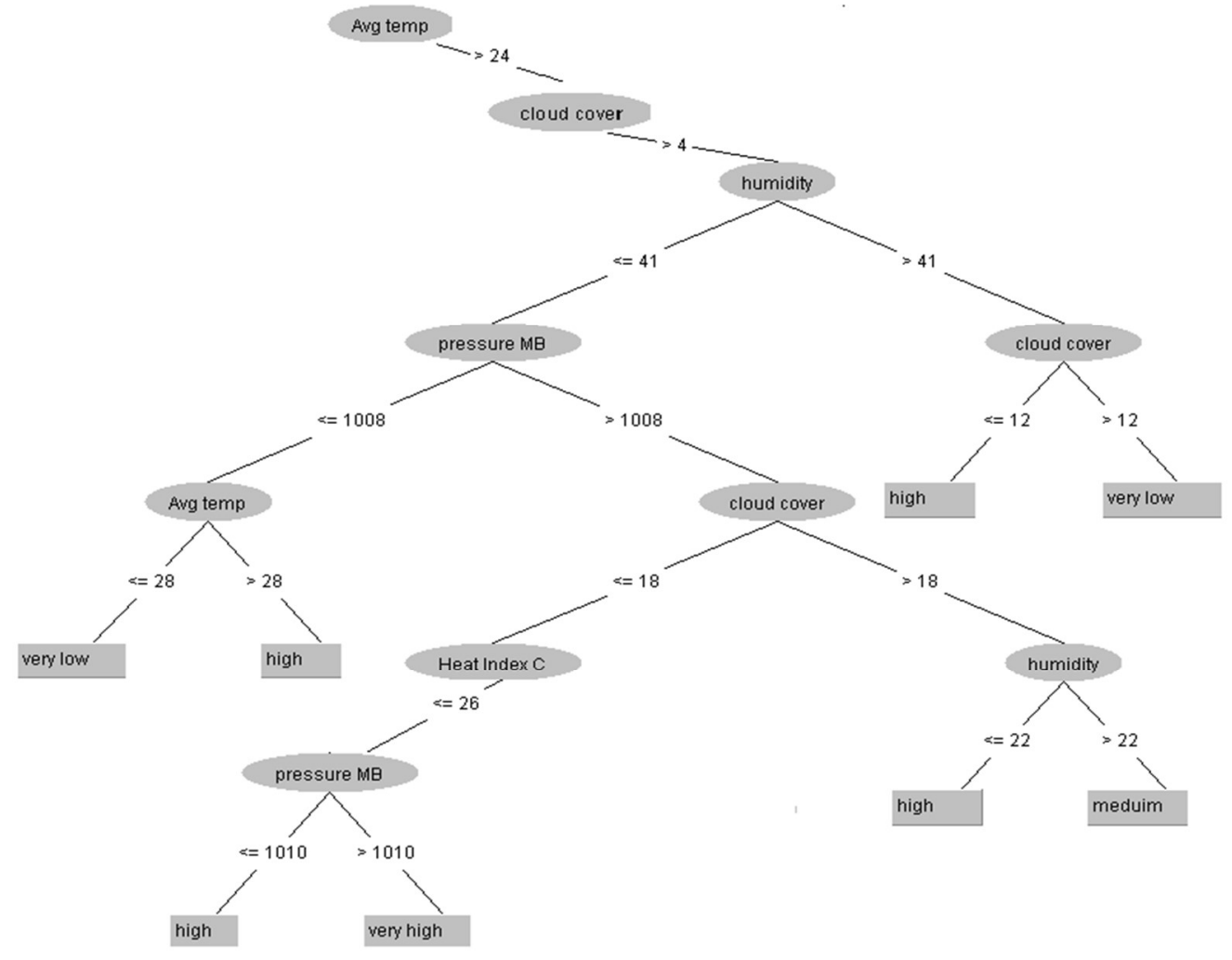

Fig. 17 Part of decision tree used in validation step 
Table 11. Sample of validation data set

\begin{tabular}{|c|c|c|c|c|c|c|c|c|}
\hline & $\Xi$ & 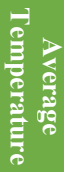 & 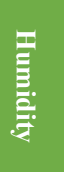 & 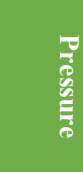 & $\begin{array}{l}\varrho \\
\varrho \\
\bar{E} \\
\varrho \\
\varrho \\
\varrho\end{array}$ & $\frac{\frac{E}{8}}{\frac{2}{8}}$ & 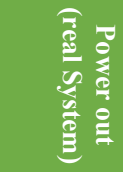 & 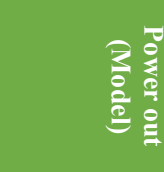 \\
\hline 1 & & 36 & 30 & 1006 & 5 & 36 & medium & medium \\
\hline 2 & & 35 & 26 & 1010 & 5 & 35 & medium & medium \\
\hline 3 & & 32 & 45 & 1012 & 5 & 33 & medium & medium \\
\hline 4 & & 26 & 44 & 1014 & 8 & 27 & medium & high \\
\hline 5 & & 27 & 24 & 1010 & 19 & 26 & medium & medium \\
\hline 6 & & 25 & 24 & 1017 & 25 & 24 & medium & medium \\
\hline 7 & & 25 & 27 & 1011 & 35 & 24 & medium & medium \\
\hline 8 & & 30 & 24 & 1008 & 6 & 29 & medium & medium \\
\hline 9 & & 28 & 41 & 1006 & 7 & 28 & medium & medium \\
\hline 10 & & 27 & 17 & 1011 & 15 & 26 & medium & medium \\
\hline 11 & & 34 & 29 & 1011 & 9 & 33 & high & high \\
\hline 12 & & 32 & 37 & 1016 & 5 & 32 & high & high \\
\hline 13 & & 30 & 48 & 1016 & 5 & 31 & high & high \\
\hline 14 & & 32 & 34 & 1015 & 13 & 31 & high & high \\
\hline 15 & & 31 & 21 & 1006 & 11 & 30 & high & high \\
\hline 16 & & 28 & 45 & 1015 & 7 & 29 & high & high \\
\hline 17 & & 29 & 43 & 1014 & 7 & 29 & high & high \\
\hline 18 & & 31 & 25 & 1008 & 12 & 29 & high & high \\
\hline 19 & & 28 & 47 & 1013 & 8 & 28 & high & high \\
\hline 20 & & 29 & 15 & 1008 & 42 & 28 & high & high \\
\hline 21 & & 29 & 25 & 1008 & 35 & 28 & high & high \\
\hline 22 & & 29 & 29 & 1008 & 19 & 28 & high & high \\
\hline 23 & & 29 & 28 & 1007 & 10 & 28 & high & high \\
\hline 24 & & 27 & 48 & 1005 & 6 & 28 & high & high \\
\hline 25 & & 28 & 29 & 1015 & 8 & 27 & high & high \\
\hline 26 & & 26 & 52 & 1014 & 9 & 27 & high & high \\
\hline 27 & & 26 & 54 & 1013 & 19 & 27 & high & very low \\
\hline 28 & & 28 & 22 & 1010 & 27 & 27 & high & high \\
\hline 29 & & 25 & 51 & 1015 & 10 & 26 & high & high \\
\hline 30 & & 27 & 22 & 1014 & 24 & 26 & high & high \\
\hline 31 & & 27 & 25 & 1010 & 33 & 26 & high & high \\
\hline 32 & & 26 & 18 & 1010 & 16 & 25 & high & high \\
\hline 33 & & 25 & 33 & 1009 & 16 & 25 & high & high \\
\hline 34 & & 25 & 21 & 1011 & 67 & 24 & high & high \\
\hline 35 & & 34 & 15 & 1014 & 6 & 32 & high & high \\
\hline 36 & & 33 & 26 & 1013 & 16 & 32 & high & high \\
\hline 37 & & 30 & 23 & 1012 & 31 & 29 & high & high \\
\hline 38 & & 26 & 29 & 1012 & 5 & 25 & very high & Very high \\
\hline 39 & & 25 & 32 & 1012 & 5 & 25 & very high & very high \\
\hline 40 & & 25 & 17 & 1012 & 10 & 24 & very high & very high \\
\hline 41 & & 25 & 31 & 1012 & 6 & 24 & very high & very high \\
\hline 42 & & 30 & 47 & 1015 & 14 & 32 & very high & very high \\
\hline 43 & & 28 & 34 & 1008 & 7 & 28 & very high & very high \\
\hline 44 & & 27 & 42 & 1008 & 20 & 27 & very high & very high \\
\hline
\end{tabular}


The prediction result by the system is highly matched by the actual PV system generation. The achieved results are shown in Table 12 and Table 13. These coefficients suggest excellent agreement between the real system and the developed model.

Table 12. Confusion matrix (validation set)

\begin{tabular}{|c|c|c|c|c|c|}
\hline Output & \multicolumn{5}{|c|}{ Real System } \\
\hline \multirow{5}{*}{$\begin{array}{l}\bar{\delta} \\
\bar{\theta} \\
\bar{\Sigma}\end{array}$} & & $\begin{array}{l}\text { Very } \\
\text { Low }\end{array}$ & Medium & High & $\begin{array}{l}\text { Very } \\
\text { High }\end{array}$ \\
\hline & $\begin{array}{l}\text { Very } \\
\text { Low }\end{array}$ & 88 & 2 & 0 & 1 \\
\hline & Medium & 4 & 77 & 1 & 2 \\
\hline & High & 1 & 3 & 68 & 5 \\
\hline & $\begin{array}{l}\text { Very } \\
\text { High }\end{array}$ & 2 & 2 & 1 & 108 \\
\hline
\end{tabular}

Table 13. Overall performance results (validation set)

\begin{tabular}{|c|c|c|c|}
\hline Precision & Recall & $\begin{array}{l}\text { F- } \\
\text { Measure }\end{array}$ & Class \\
\hline 0.967 & 0.926 & 0.946 & very low \\
\hline 0.916 & 0.916 & 0.916 & Medium \\
\hline 0.883 & 0.971 & 0.924 & high \\
\hline 0.955 & 0.931 & 0.942 & very high \\
\hline \multicolumn{3}{|c|}{ Correctly Classified Percentage } & $93.425 \%$ \\
\hline \multicolumn{3}{|c|}{ Kappa statistic } & 0.912 \\
\hline \multicolumn{3}{|c|}{ Total Number of Instances } & 365 \\
\hline
\end{tabular}

\section{ACKNOWLEDGMENT}

The authors wish to express their thanks for the support of Tafila Technical University. The authors very much appreciate the support by Kawar Energy Company and Electricity Distribution Company (EDCO).

\section{CONCLUSION}

In this paper, a new model of $1 \mathrm{MWp}$ TTU PV system is analyzed using intelligent decision classifier. The developed system gives the relation between the generated output power and different weather conditions. The model of the system is built based on real output power and weather databases. The results show high accuracy and precision. In the future work different intelligent techniques will be used to increase system accuracy and precision.

\section{References}

[1] A. Al-Azzam and Amani, 'The Grid (Opportunity vs. Challenges)', Jordanian Forum Renew. Energy, 2014.

[2] V. Khare, S. Nema, and P. Baredar, 'Solar-wind hybrid renewable energy system: A review', Renew. Sustain. Energy Rev., vol. 58, pp. 23-33, 2016.

[3] V. Vittal and T. G. Heydt, 'Impact of large scale PV generation', pp. 1-1, 2014.

[4] R. Shah, N. Mithulananthan, A. Sode-Yome, and K. Y. Lee, 'Impact of large-scale PV penetration on power system oscillatory stability', IEEE PES Gen. Meet. PES 2010, pp. 1-7, 2010.

[5] P. S. Panel and P. Affairs, 'Integrating Renewable Electricity on the Grid A Report by the APS Panel on Public Affairs', Leadership, pp. 1-38, 2010.

[6] G. Balaban, G. C. Lazaroiu, V. Dumbrava, and C. A. Sima, 'Analysing Renewable Energy Source Impacts on Power System National Network Code / Romania', 2017.

[7] Obeidat, M.A. and Al-Sarayrah, R.M., "The Impact of Renewable Energy Integration on Stability of the Jordanian National Grid," International Journal of Computer Applications, 975, p.8887, 2019.

[8] Ayman M. Mansour, Murad M. Alaqtash, Mohammad Obeidat "Intelligent Classifiers of EEG Signals for Epilepsy Detection," WSEAS Transactions on Signal Processing, Volume 15, 2019.

[9] Jafar.Abu Khait, Ayman M Mansour and Mohammad Obeidat, "Classification based on Gaussian-kernel Support Vector Machine with Adaptive Fuzzy Inference System," PRZEGLĄD ELEKTROTECHNICZNY. Vol 5, pp 16-24, 2018.

[10]B. Hawashin et al., "Efficient Texture Classification Using Independent Component Analysis," 2019 IEEE Jordan International Joint Conference on Electrical Engineering and Information Technology (JEEIT), Amman, Jordan, pp. 544-547, 2019.

[11] Ayman M. Mansour, "Decision Tree-Based Expert System for Adverse Drug Reaction Detection using Fuzzy Logic and Genetic Algorithm," International Journal of Advanced Computer Research (IJACR), Vol 8(36), 2018.

[12] Mohammad A. Obeidat and Ayman M. Mansour, "EEG Based Epilepsy Diagnosis System using Reconstruction Phase Space and Naïve Bayes Classifier," WSEAS Transactions on Circuits and Systems, Volume 17, 2018.

[13] Ayman M. Mansour, "Texture Classification using Naïve Bayes Classifier," International Journal of Computer Science and Network Security (IJCSNS), vol. 18, no. 1, January 2018

[14]Bilal Hawashin, Ayman M. Mansour and Shadi Aljawarneh, "An Efficient Feature Selection Method for Arabic Text Classification," International Journal of Computer Applications (IJCA), vol. 83, no. 17, pp. 1-6, December 2013. 
[15]D.A. Al Nadi and Ayman Mansour, "Independent Component Analysis (ICA) for texture classification", 5th International Multi-Conference on Signals and Devices, IEEE SSD, 2008.

[16] Almonacid, F. J. M. F., Rus, C., Hontoria, L., \& Munoz, F. J. "Characterisation of PV CIS module by artificial neural networks. A comparative study with other methods," Renewable Energy, 35(5), 973-980,2010.

[17] Garud, Kunal Sandip, Simon Jayaraj, and Moo-Yeon Lee. "A review on modeling of solar photovoltaic systems using artificial neural networks, fuzzy logic, genetic algorithm and hybrid models." International Journal of Energy Research, 2020.

[18] Almonacid, Florencia, et al. "Review of techniques based on artificial neural networks for the electrical characterization of concentrator photovoltaic technology." Renewable and Sustainable Energy Reviews 75 : 938-953, 2017.

[19] Rodríguez, Fermín, et al. "Predicting solar energy generation through artificial neural networks using weather forecasts for microgrid control." Renewable energy 126 : 855-864,2018.

[20] Monteiro, Raul VA, et al. "Estimating photovoltaic power generation: performance analysis of artificial neural networks, Support Vector Machine and Kalman filter." Electric Power Systems Research 143:643-656, 2017.

[21] Kazem, Hussein A., Jabar H. Yousif, and Miqdam T. Chaichan. "Modeling of daily solar energy system prediction using support vector machine for Oman." International Journal of Applied Engineering Research 11.20: 10166-10172, 2016.

[22]Zendehboudi, Alireza, M. A. Baseer, and R. Saidur. "Application of support vector machine models for forecasting solar and wind energy resources: A review." Journal of cleaner production 199: 272-285, 2018.

[23] Bae, Kuk Yeol, Han Seung Jang, and Dan Keun Sung. "Hourly solar irradiance prediction based on support vector machine and its error analysis." IEEE Transactions on Power Systems 32.2: 935-945, 2016.

[24] Mojumder, Juwel Chandra, et al. "Application of support vector machine for prediction of electrical and thermal performance in PV/T system." Energy and Buildings 111: 267-277,2016.

[25] Liu, Zhao, and Ziang Zhang. "Solar forecasting by KNearest Neighbors method with weather classification and physical model." 2016 North American Power Symposium (NAPS). IEEE, 2016.

[26] Kartini, Unit Three, and Chao Rong Chen. "Short term forecasting of global solar irradiance by k-nearest neighbor multilayer backpropagation learning neural network algorithm." Proceedings of the International Conference on Graphics and Signal Processing. 2017.

[27] Valgaev, Oleg, Friederich Kupzog, and Hartmut Schmeck. "Building power demand forecasting using K-nearest neighbours model-practical application in Smart City Demo Aspern project." CIRED-Open Access Proceedings Journal 2017.1: 1601-1604, 2017.

[28] Mercado, Katheryn Donado, Jamer Jiménez, and M. Christian G. Quintero. "Hybrid renewable energy system based on intelligent optimization techniques." 2016 IEEE
International Conference on Renewable Energy Research and Applications (ICRERA). IEEE, 2016.

[29] Ebrahimi, S. Mohammadreza, et al. "Parameters identification of PV solar cells and modules using flexible particle swarm optimization algorithm." Energy 179: 358372, 2019.

[30] Rajan, Naik Aashay, et al. "Solar PV array reconfiguration using the concept of standard deviation and genetic algorithm." Energy Procedia 117: 1062-1069, 2017.

[31] Kumari, P. Ashwini, and P. Geethanjali. "Adaptive genetic algorithm based multi-objective optimization for photovoltaic cell design parameter extraction." Energy Procedia 117: 432-441, 2017.

[32] Ordiano, Jorge Ángel González, et al. "Photovoltaic power forecasting using simple data-driven models without weather data." Computer Science-Research and Development 32.1-2: 237-246, 2017.

[33] Quinlan JR. "C4. 5: programs for machine learning," Elsevier; 2014.

[34] Wu X, Kumar V, Quinlan JR, Ghosh J, Yang Q, Motoda $\mathrm{H}$, et al. "Top 10 algorithms in data mining," Knowledge and Information Systems volume 14, pp 1-37, 2008.

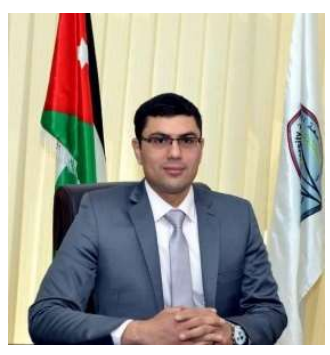

Dr. Ayman M Mansour received his Ph.D. degree in Electrical Engineering from Wayne State University in 2012. Dr. Mansour received his M.Sc degree in Electrical Engineering from University of Jordan, Jordan, in 2006 and his B.Sc degree in Electrical and Electronics Engineering from University of Sharjah, UAE, in 2004. He graduated top of his class in both Bachelor and Master. Currently, Dr. Mansour is an Associate Professor in the Department of Communication and Computer Engineering, Tafila Technical University, Jordan. He is also the director of the Energy Research Center at Tafila Technical University. His areas of research include Communication Systems, Multi-agent Systems, Fuzzy Systems, Data Mining and Intelligent Systems. He conducted several researches in his area of interest. Dr. Mansour is a member of IEEE, Michigan Society of Professional Engineers, IEEE Honor Society (HKN), Society of Automotive Engineers (SAE), Tau Beta Pi Honor Society, Sigma Xi and Golden Key Honor Society.

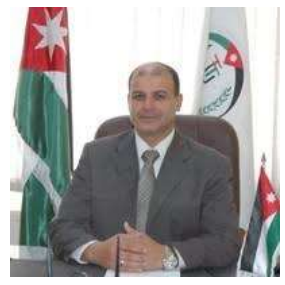

Prof, Jalal M. Abdallah was born in Amman, Jordan. He received his M.S.1994 and Ph.D.1998 in electrical engineering from Vinitsa Stat Technical University, Ukraine. Since 2005, he has joined Tafila Technical University where he is currently a Professor at the electrical Engineering Department and the vice president of academic affairs. Dr. Jalal Abdallah main research interests are power system analysis, monitoring, and diagnostic of high-voltage power transformers. 


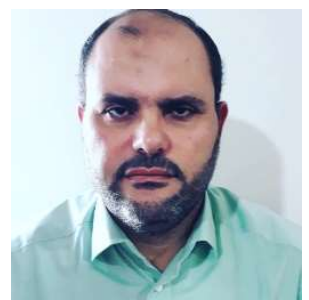

Dr. Mohammed Obeidat Received his $\mathrm{PhD}$ in Electrical Engineering from Wayne State University in 2013, M.Sc degree in Electrical Engineering was from Yarmouk University, Jordan in 2006, and B.Sc degree in Electrical Engineering from Jordan University of Science \& Technology, Jordan in 1999. $\mathrm{He}$ is an Associate professor in power and mechatronics department at Tafila Technical University.
He is a member of IEEE, Tau Beta PI Honor Society and Golden Key Honor Society. He was given the honor to be a Sigma Xi member from the Board of Governor, in 2012. He demonstrated excellent research and academic abilities as well as professional potentials.

Dr. Obeidat has published several journal papers. Dr. Obeidat research of interest in the field of intelligent control systems, renewable energy, intelligent systems, and mechatronics

Creative Commons Attribution License 4.0 (Attribution 4.0 International, CC BY 4.0)

This article is published under the terms of the Creative Commons Attribution License 4.0

https://creativecommons.org/licenses/by/4.0/deed.en_US 